\title{
The study of knowledge, attitude and practice about abortion and technology at the tertiary centre in the region of Mewar, Rajasthan, India
}

\author{
Archana Bamniya, Savitri Verma*
}

Department of Obstetrics and Gynecology, R. N. T. Medical College, Udaipur, Rajasthan, India

Received: 06 June 2018

Accepted: 05 July 2018

*Correspondence:

Dr. Savitri Verma,

E-mail: savitriverma1997@gmail.com

Copyright: () the author(s), publisher and licensee Medip Academy. This is an open-access article distributed under the terms of the Creative Commons Attribution Non-Commercial License, which permits unrestricted non-commercial use, distribution, and reproduction in any medium, provided the original work is properly cited.

\begin{abstract}
Background: Availability of safe, effective and acceptable abortion-care services is one of the most important aspects of women's reproductive health. Unsafe abortion is one of the four main causes of maternal mortality and morbidity. To study knowledge, attitude, and practice (KAP) regarding abortion and methods used among/for women of child bearing age to formulate recommendation for improving the safe abortion services

Methods: This prospective study was done among 100 cases who came for MTP at department of Obstetrics and Gynaecology, RNT medical college, Udaipur during November and December 2017. Data was collected using a selfsemi structured questionnaire related to abortion technology.

Results: $58 \%$ of women knew that there were provisions for abortion in public hospitals but only $38 \%$ of them knew that abortion should be performed/carried out by a trained doctor only. $70 \%$ of the women knew that there were medicines available for abortion (MMA) but only $20 \%$ of them knew how and from where to avail them. $69 \%$ knew about other methods and that D and $\mathrm{E}$ can be done in hospitals both at private and public sector, $25 \%$ knew the complications related to unsafe abortion. About the attitude almost all women wanted abortion should be done if needed only $10 \%$ knew that abortion is legal. $66 \%$ of women consider MMA to be safe and $27 \%$ of women consider contraception is necessary.

Conclusions: Majority of women have positive attitude towards the abortion. The most prefer method chosen for abortion was medical method of abortion (MMA).
\end{abstract}

Keywords: Dilatation and evacuation (D and E), Medical method abortion (MMA)

\section{INTRODUCTION}

Abortion is defined as the termination of pregnancy by the removal or expulsion from the uterus of a fetus or embryo prior to viability. An abortion can occur spontaneously, in which case it is usually called a miscarriage, or it can be purposely induced. The term abortion most commonly refers to the induced abortion of a human pregnancy. ${ }^{1}$ Approximately 210 million pregnancies occur each year worldwide. One third of these (or 75 million) pregnancies end in stillbirth and a fifth in induced abortions. Most abortions result from unintended pregnancies. A pregnancy can be intentionally aborted in several ways. The manner selected often depends upon the gestational age of the embryo or fetus, which increases in size as the pregnancy progresses. Specific procedure may also be selected due to legality, regional availability, and doctor or patient preference. $^{2}$

Between 10-50\% of women who undergo unsafe surgical abortions need medical care for complications. The most 
common complications are incomplete abortions, infections (sepsis), haemorrhages and injuries to internal organs such as perforation of the uterus. Long term health problems include chronic pain, pelvic inflammatory disease and infertility.

We have a liberal abortion law which makes abortion available on request for social, ethical or eugenic reasons. The most common reason why women resort to unsafe abortion is unintended pregnancy. The common causes of unintended pregnancies are lack of access to, or failure to use, a contraceptive method and sometimes failure of contraceptive method itself. Other reasons may be a pregnancy occurring as a result of sexual coercion or rape and a variety of socio economic reasons. Safe and legal abortion is considered a key intervention for improving women's health and quality of life.

Abortion has been made legal in India for decades now since the introduction of the Medical Termination of Pregnancy (MTP) act 1971. Even then unsafe abortion is the cause of death of about 3500 women each year while many more face morbidity. ${ }^{3}$

Various steps have been taken by the government of India at the national and state levels to integrate comprehensive abortion care interventions across maternal health and family planning.

By promoting safer technologies like Electric Vacuum Aspiration (EVA), Manual Vacuum Aspiration (MVA) and Medical Methods of Abortion (MMA) using a combination of two drugs i.e.; Mifepristone and Misoprostol, women's access to safe abortion services has further been strengthened globally and in India.

Numerous barrier limits hinder access to safe services such as shortage of trained providers, lack of infrastructure at the facilities and lack of information about legality and availability of services among women and the community.

Access to information is a key determinant of safe abortion. The provision of information about safe legal abortion is crucial to protect women's health and safeguard their human rights. This study was conducted with the objectives of assessing the knowledge, attitude and practice regarding abortion and technology to evaluate socio-demographic profile of women seeking abortion like age, parity, socioeconomic condition, education, duration of pregnancy and reasons to opt for the termination of pregnancy.

\section{METHODS}

\section{Study area and period}

This prospective study was done among 100 cases at the Dept. Of obstetrics and gynaecology in R.N.T. Medical College, Udaipur during November and December of
2017. R. N. T. Medical College is one of the many higher institutions that is located in the north-western part of India. It is situated near the tribal belt of south Rajasthan.

\section{Study design/ methodology}

An institutional based cross-sectional questionnaire was prepared and the women who came for MTP in our hospital were assessed.

Questions pertaining to women's knowledge, attitude, perception, use of medical abortion, and use of emergency contraception were asked. The study was carried out by using responses in the proforma given. Leading questions or suggestive questions were not asked to avoid biasing and overestimation. The information collected was then analysed.

\section{Data collection}

Data collection was done after the approval of the institute's ethical committee and the informed consent of the women were taken. All the women undergoing termination of pregnancy were asked to fill a self-semi structured questionnaire that tested their knowledge regarding the various methods of termination, preference of one method, reasons about the legal issues and complications regarding the procedure and after experience.

$\mathrm{P}$ value $<0.05$ was considered statistically significant.

\section{Inclusion Criteria}

Women of reproductive age coming for medical termination of pregnancy in the months of November and December of 2017 were included in the study. They were picked up from the Out-Patient Department of Pannadhai Mahila Chikitsalaya.

\section{Exclusion criteria}

Those women, who presented after a spontaneous abortion and came for termination of pregnancy because the foetus had a congenital anomaly or if her life was in danger because of the pregnancy and would not be expected to use contraceptives in near future were excluded from the study. Those women who did not give consent to be a part of present study were also not considered study.

\section{RESULTS}

\section{Socio-demographic characteristics of respondents}

From the total of 100 women involved in this study the largest no. of women $56 \%$ belonged to age group of 2630 years followed by $25 \%$ were age group of $21-25$ years, $75 \%$ of the women were from urban areas and $25 \%$ from rural. Majority (33\%) of the women undergoing 
termination were of parity-1, 28\% were of parity-2, $23 \%$ of parity- 3 and $40 \%$ of them were illiterate (Table 1 ).

Table 1: Socio-demographic characteristics of respondents, November 2017.

\begin{tabular}{|c|c|c|}
\hline \multicolumn{2}{|l|}{ Demographic variables } & $\begin{array}{l}\text { Frequency } \\
(\%)\end{array}$ \\
\hline \multirow{4}{*}{ Age group } & $15-20$ & 5 \\
\hline & $21-25$ & 25 \\
\hline & $26-30$ & 56 \\
\hline & $31-35$ & 14 \\
\hline \multirow{2}{*}{ Marital status } & Married & 99 \\
\hline & Unmarried & 1 \\
\hline \multirow{4}{*}{ Parity } & Gravida 1 P0 & 16 \\
\hline & P1 & 33 \\
\hline & $\mathrm{P} 2$ & 28 \\
\hline & $\mathrm{P} 3$ or more & 23 \\
\hline \multirow{2}{*}{ Residential area } & Urban & 75 \\
\hline & Rural & 25 \\
\hline \multirow{5}{*}{ Socioeconomic group } & Grade 1 & 12 \\
\hline & Grade 2 & 12 \\
\hline & Grade 3 & 24 \\
\hline & Grade 4 & 30 \\
\hline & Grade 5 & 22 \\
\hline \multirow{4}{*}{ Education } & Illiterate & 40 \\
\hline & Primary & 23 \\
\hline & High school & 26 \\
\hline & Graduation & 11 \\
\hline
\end{tabular}

Unplanned pregnancy was the indication for termination in $43 \%$ cases, failure of contraception in $37 \%$ and social factors in $20 \%$ cases (Table 2). About $5 \%$ women took drugs for abortion by themselves after consultation with a doctor, drugs were provided by the husband in $1 \%$ cases, by family members and relatives in $10 \%$ cases and directly through a chemist in $10 \%$ of the cases (Table 3 ).

Table 2: Indications of abortion in women.

\begin{tabular}{|l|l|}
\hline Indications for termination & Number \\
\hline Unplanned pregnancy & $43 \%$ \\
\hline Failure of contraception & $37 \%$ \\
\hline Social factor & $20 \%$ \\
\hline
\end{tabular}

Table 3. Service provider.

\begin{tabular}{|l|l|}
\hline Drug provided by & Numbers $(\mathbf{n}=\mathbf{2 6})$ \\
\hline Self & 5 \\
\hline Husband & 1 \\
\hline Family & 10 \\
\hline Chemist & 10 \\
\hline
\end{tabular}

\section{Knowledge of respondents}

Among respondents $70 \%$ had ever heard about safe abortion and 69\% knew about the Dilatation and Evacuation method of abortion. 58\% of the respondents know safe abortions are performed at government approved institutions only. $38 \%$ of them knew that safe abortion procedures were done by trained doctors. $10 \%$ of the respondents knew that MTP is legalised. 25\% of the respondents knew about the complications of an unsafe abortion. $27 \%$ of them were aware about the usage of contraceptives.

Maximum number of the patients were aware about some or the other methods of contraception. A majority of them $(89 \%)$ were aware about the various sterilization techniques available.

$76 \%$ of the respondents were aware about the usage of intrauterine contraceptive devices such as $\mathrm{Cu}-\mathrm{T}$. 70\% knew about oral contraceptive pills. $64 \%$ of the respondents knew about male sterilization techniques. Other contraceptive methods including condoms, injectable, medical abortion were also known to the respondents. $10 \%$ of them were unaware of any of the various methods of contraception. $2 \%$ were aware of emergency contraception. Attitudes of respondents on safe abortion.

Table 4. Knowledge about abortion and technology.

\begin{tabular}{|c|c|c|}
\hline Variables & & $\begin{array}{l}\text { Percent } \\
(n=100)\end{array}$ \\
\hline \multirow[t]{2}{*}{$\begin{array}{l}\text { Methods of safe } \\
\text { abortion are you } \\
\text { aware of? }\end{array}$} & MMA & 70 \\
\hline & $\mathrm{D}$ and $\mathrm{E}$ & 69 \\
\hline \multirow[t]{3}{*}{$\begin{array}{l}\text { In accordance } \\
\text { with the MTP } \\
\text { Act do you } \\
\text { know that }\end{array}$} & $\begin{array}{l}\text { MTPs are performed } \\
\text { independently in a } \\
\text { hospital established or } \\
\text { maintained by the } \\
\text { government or a } \\
\text { training institute? }\end{array}$ & 58 \\
\hline & $\begin{array}{l}\text { Trained doctors } \\
\text { perform MTP? }\end{array}$ & 38 \\
\hline & $\begin{array}{l}\text { MTPs are legalised in } \\
\text { India? }\end{array}$ & 10 \\
\hline \multirow{2}{*}{$\begin{array}{l}\text { Do you know } \\
\text { the } \\
\text { complications of } \\
\text { an unsafe } \\
\text { abortion? }\end{array}$} & Yes & 25 \\
\hline & No & 75 \\
\hline \multirow{2}{*}{$\begin{array}{l}\text { Are you aware } \\
\text { about the use of } \\
\text { contraceptive } \\
\text { methods? }\end{array}$} & Yes & 27 \\
\hline & No & 73 \\
\hline
\end{tabular}

Out of the 100 women who came for termination $53 \%$ opted only for termination and were unwilling to opt for any method contraception.

$42 \%$ women wanted temporary methods of contraception after termination. And 5\% were wiling for permanent sterilisation. $66 \%$ of the respondents preferred MMA, while $34 \%$ opted for D and E method of safe abortion. 
Table 5. Awareness of contraceptive methods.

\begin{tabular}{|l|l|}
\hline Method & A ware respondents $(\mathbf{n = 1 0 0})$ \\
\hline Natural & 30 \\
\hline Condom & 60 \\
\hline Oral pill & 70 \\
\hline Injectable & 30 \\
\hline Cu-T & 76 \\
\hline Emergency contraceptior & 2 \\
\hline Female sterilization & 89 \\
\hline Male sterilization & 64 \\
\hline Medical abortion & 37 \\
\hline None of the above & 10 \\
\hline
\end{tabular}

\section{DISCUSSION}

Unsafe abortions account for $13 \%$ of all maternal deaths. ${ }^{4}$ Almost all the deaths and morbidity from unsafe abortions occur in countries where abortions are severely restricted and abortion laws are very strict. Every year about 47,000 women die from complications of unsafe abortions and an estimate of 5 million women suffer temporary or permanent disabilities. ${ }^{5}$ The barriers which impede women from reaching the required medical services and attention include illiteracy, lack of information, lack of access to health facilities, confidentiality, privacy and respect towards females undergoing the abortion process.

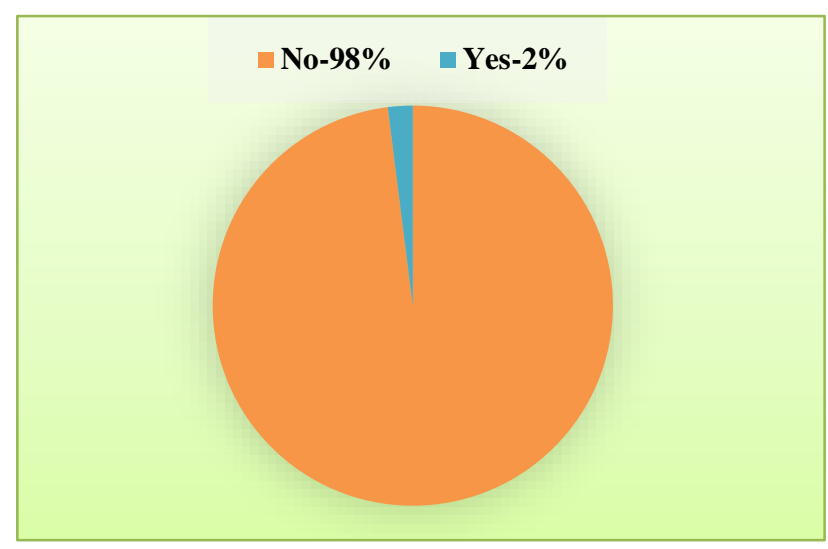

Figure 1: Knowledge of respondents about emergency contraception.

In present study most of the women who came for termination of pregnancy were from the age group of 25$30(56 \%)$, Guleria K et al, Bahadur et al, Shrivasatava et al, Patel et al, in their studies found the same. ${ }^{6-9}$ Majority of them were married (99\%) Guleria K et al (91.4\%). ${ }^{6}$

$33 \%$ of the women were of parity 1 followed by parity 2 (28\%). $74 \%$ of them were from urban and $25 \%$ were from rural areas respectively, but the majority of the women from urban regions were from urban slum areas. Agrawal and Salhan 10 also noted that $32 \%$ were from rural, $24 \%$ from urban, $44 \%$ from urban slum areas. ${ }^{10}$
In present study, majority of the women (30\%) belonged to class 4 socio economic status, supported by B.C. Shivkumar. ${ }^{11} 74 \%$ from middle class, Bahadur et al and $53 \%$ were from lower middle class. Poor socio-economic conditions may compel many women to depend and seek services from unqualified providers. ${ }^{7}$

Majority of the patients $(40 \%)$ were uneducated. In the study conducted by Shivkumar et al $57 \%$ were uneducated11. In this stratum of society there is a lack of awareness about contraceptive methods and most of the pregnancies were unplanned. $47 \%$ of women became aware of abortion procedures through the media and $18.85 \%$ from their relatives, Shrivastav et al. ${ }^{8}$ In study by Wiebe ER, Sandhu S. women received information about abortion services from a physician $60 \%$, friends and family members $(5.3 \%){ }^{12}$ The main reason for undergoing abortion was failed contraception followed by unplanned pregnancies (32\%). In the study of Shivkumar et al unplanned $(30.7 \%)$, contraceptive failure $(29.3 \%) .^{11}$ Inadequate income $(26.7 \%)$ as a reason for opting abortion.

In present study women received medicine directly from a chemist $(90 \%)$, by relatives $-37 \%$ and by themselves $10 \%$. In Dhillon BS et al study (42.8\%) from husband, Shrivastava et al8 study (42.38\%) from chemist. ${ }^{13}$ (12\%) of women did not go directly to the doctor due to lack of information and $50 \%$ due to fear and social factors. In study of $\mathrm{K}$ Coyaji three most important reason for choosing medical abortion were avoiding hospital admission, fear of surgery and greater convenience.

In present study (42\%) accepted temporary contraception and 53\% did not accept any method of contraception. In S.Mittal et al study (39.8\%) did not accept any contraception. ${ }^{14}$

\section{CONCLUSION}

Unsafe abortion is one of the four main causes of maternal morbidity. Most common reason for unsafe abortion is that safe abortion services are frequently not available, even when they are legal for a variety of indications. An enabling environment and provisions of information is needed to ensure that every woman who is legally eligible has ready to access to safe abortion care. With the moto of safe motherhood that every life count and so woman should be safe from unsafe abortion practice. Udaipur being serving the tribal belt, where women are shy and of lower socio-economic status with poor literacy so to reach them we should involve Para health workers like ASHA, LHV, ANM, counsellor to bridge the gap for safe abortion and contraception services to women.

Funding: No funding sources

Conflict of interest: None declared

Ethical approval: The following study has been approved by PDMC Ethical Committee, RNT Medical College 


\section{REFERENCES}

1. Shah I, Åhman E. Unsafe abortion: global and regional incidence, trends, consequences, and challenges. J Obstet Gynaecol Canada. 2009;31(12):1149-58.

2. Cope J., Abortion Law Reform in Apartheid South Africa. Pietermaritzburg, South Africa: Hadeda Books. 1993

3. World Health Organization (WHO: Unsafe abortion global and regional estimates of the incidence of unsafe abortion and associated mortality in 2008. -6th Ed.

4. Unsafe abortion incidence and mortality. Global and regional levels in 2008 and trends during 1990-2008.

5. World Health Organization (WHO), Unsafe Abortion: Global and Regional Estimates of the Care.

6. Guleria K, Bansal S, Agarwal N, Grover V. Women with septic abortion: who, how and why? A prospective study from tertiary care hospital in India. Indian J Public Health. 2006;50(2):95-6.

7. Bahadur A, Mittal S, Sharma J B, Sehgal R. Sociodemographic profile of women undergoing abortion in tertiary centre. Arch Gynecol Obstet. 2008;278:329-32.

8. Shrivastava N. Yadav N. The study of knowledge, attitude and practice of medical abortion in women at a tertiary centre. IOSR. 2015;14(12):2279-0861.
9. Patel R, Ghosh R., KAP study of contraception in clients undergoing MTP and sterilization in Gujarat, India. Int J Reprod Contracept Obstet Gynecol. 2017;6(6):2503-6

10. Agarwal S and Salhan S. Septic abortion - current scenario in a tertiary care hospital. J Obstet Gynecol India. 2008;58(2):147-51.

11. Shivakumar BC, Vishvanath D, Srivastava PC. A profile of abortion cases in a tertiary hospital. J Indian Acad Forensic Med. 2011;33(1):33-8.

12. Wiebe ER, Sandhu S. Access to abortion: what women want from abortion services. J Obstet Gynaecol Can. 2008;30(4):327-31.

13. Dhillon BS, Chandhiok N, Kambo I, Saxena NC. Induced abortion and concurrent adoption of contraception in the rural areas of India (An ICMR task force study). Indian J Med Sci. 2004;58(11):478-84.

14. Mittal S, Bahadur A, Sharma JB. Survey of the attitude to, knowledge and practice of contraception and medical abortion in women attending a family planning clinic. J Turkish- German Gynecol Assoc. 2008;9(1):29-34.

Cite this article as: Bamniya A, Verma $\mathrm{S}$, The study of knowledge, attitude and practice about abortion and technology at the tertiary centre in the region of Mewar, Rajasthan, India. Int J Reprod Contracept Obstet Gynecol 2018;7:3320-4. 